\section{P1-283 TRENDS IN AGE AT MENARCHE AND MENOPAUSE OF WOMEN IN VALENCIA COMMUNITY BORN IN DURING 1927-1964 PERIOD}

doi:10.1136/jech.2011.142976e.75

\begin{abstract}
1,2E Pérez-Sanz, ${ }^{* 1,2} \mathrm{R}$ Peiró-Pérez, ${ }^{1,2} \mathrm{D}$ Salas, ${ }^{1} \mathrm{G}$ Vallés, ${ }^{1,2} \mathrm{~J}$ Miranda, ${ }^{1,2} \mathrm{~J}$ Ibañez, ${ }^{1}$ A Molina-Barceló. 'Centro Superior de Investigación en Salud Pública, Valencia, Spain; ${ }^{2}$ Dirección General de Salud Pública, Valencian Community, Spain
\end{abstract}

Objective To describe and analyse the trend in age at menarche and menopause of women who have attended the breast cancerscreening program in the Valencian Community (VC) from 1992 to 2009 (born between 1927 and 1964).

Materials and Methods Between 1992 and 2009, a retrospective cohort of participants in a population-based breast cancer-screening program in the VC was assessed. The study population was 695313 women, 45-69 years. Trends in menarche and menopause aged by educational level (EL), nationality and territory by born cohorts were analysed. A regression analysis by the Joint-Point for the tendency was calculated.

Results The age of menarche is earlier every cohort, 13.31 years $(1927-1929) 12.59$ years $(1960-1964)(p<0.00001)$ by EL, mean 12997 low EL vs 12492 university EL $(p<0001)$, being Spanish 12722 vs $13076(\mathrm{p}<0.0001)$ and living in urban area $(12717$ vs $12788)(p<0.0001)$. While these differences were very marked at the beginning of the period under study these being reduced in the last cohort. Joint point regression analysis shows significant differences in trend by varibles analysed. The age of natural menopause was 49.262 years in the 1927-1929 cohort, and 49.866 years in 1945-1949 ( $p<0.0001)$. Women with a low EL have an average age of menopause earlier than women of higher EL (49.531 vs 49.822) $(p<0.001)$. Regression analysis of the trend shows that the delay was more pronounced for women with no education and primary studies $(\mathrm{p}<0.0001)$.

Conclusions Menarche has advanced age and menopause is delayed, making broader reproductive cycles exist and different by the social variables studied.

\section{P1-284 VARIATION IN ESTIMATED TEN-YEAR CARDIOVASCULAR RISK ACROSS FOUR RISK SCORING TOOLS IN BOTH A GENERAL POPULATION SAMPLE AND AN OCCUPATIONAL SETTING}

doi:10.1136/jech.2011.142976e.76

${ }^{1} \mathrm{D} 0$ O'Donovan, ${ }^{1} \mathrm{~S}$ Byrne, ${ }^{2} \mathrm{M}$ Loughrey, ${ }^{2} \mathrm{G}$ Browne, ${ }^{2} \mathrm{~T}$ Fitzgerald, ${ }^{2}$ Perry, ${ }^{1} \mathrm{~L}$ Sahm. ${ }^{1}$ Pharmaceutical Care Research Group, School of Pharmacy, University College Cork, Cork, Ireland; '2Department of Epidemiology, University College Cork, Cork, Ireland

Introduction Several screening tools are now available to estimate 10year risk of cardiovascular disease (CVD). This study aimed to quantify the differences in CVD risk estimates derived from four widely-used risk scoring tools: Framingham, ORISK2, ASSIGN and SCORE with each tool applied in both a primary care and an occupational screening setting.

Methods The primary care sample data were derived from a crosssectional study of 1016 men and women aged 50-69 years (median age 59 years, $48.3 \%$ male), recruited from 17 primary care practice lists in the south of Ireland. The occupational sample data were derived from a sample of 311 workers, aged 20-63 years (median age 35 years, $72 \%$ male), mainly skilled IT and administrative staff, recruited in the workplace. All participants received a standard CVD risk assessment including smoking history and measurement of BP and lipid profile. High CVD risk was defined as 10-year risk $>20 \%$ for Framingham, QRISK2 and ASSIGN, and $>5 \%$ for SCORE.
Results In the primary care population the proportion of participants with high 10-year CVD risk ranged from 12.8\% (ORISK2) to $33.1 \%$ (SCORE). In the occupational setting, the proportion of participants with either intermediate or high 10-year CVD risk ranged from $1.3 \%$ (SCORE) to $35.1 \%$ (Framingham).

Conclusion This study highlights significant differences between four widely-used CVD risk scoring tools. The differences largely reflect variation in the CVD end points (morbidity or mortality) and risk thresholds used in the tools. This is a potential source of difficulty and confusion for practitioners and policy makers.

\section{P1-285 USE OF LINEAR SPLINE MODELS TO DESCRIBE BI-ETHNIC DIFFERENCES IN EARLY CHILDHOOD GROWTH: FINDINGS FROM THE BORN IN BRADFORD BIRTH COHORT STUDY}

doi:10.1136/jech.2011.142976e.77

${ }^{1,2} \mathrm{E}$ Petherick, ${ }^{*} \mathrm{~L}$ Fairley, ${ }^{3} \mathrm{~L}$ Howe, ${ }^{3} \mathrm{D}$ Lawlor, ${ }^{4} \mathrm{~K}$ Tilling, ${ }^{2} \mathrm{~J}$ Wright. ${ }^{1}$ Paediatric Epidemiology Group, University of Leeds, Leeds, UK; ${ }^{2}$ Bradford Institute for Health Research, Bradford, UK; ${ }^{3}$ MRC Centre for Causal Analyses in Translational Epidemiology, Bristol University, Bristol, UK; ${ }^{4}$ School of Social and Community Medicine, University of Bristol, Bristol, UK

Introduction Size at birth differs between South Asian and White European infants, but little is known about differences in growth in later infancy. We use multilevel linear spline models to describe ethnic differences in growth of infants from the Born in Bradford study (BIB).

Methods Data for 1378 singleton births from BIB with follow-up visits at 6, 12 and 18 months were used (614 White and 764 Pakistani infants). Weight and length data from clinic visits and routine measurements were used. Mulitlevel linear spline models with knot points at 4 and 10 months were fitted separately for weight and length including interactions with ethnicity and sex.

Results Models for weight and length with knot points at 4 and 10 months fitted the data well; the differences between actual and predicted measurements were small in each period. There were ethnic differences in weight and length at birth; Pakistani boys were on average $0.23 \mathrm{~kg}$ lighter ( $95 \% \mathrm{CI}-0.31$ to -0.14 ) and $1.05 \mathrm{~cm}$ shorter $(-1.48$ to -0.61$)$ than White boys, while Pakistani girls were $0.16 \mathrm{~kg}$ lighter $(-0.24$ to -0.08$)$ than White girls with no significant difference in length. The gains in weight in each time period were similar for both ethnicities. Pakistani boys and girls gained length faster than their White peers between 0 and 4 months.

Conclusions Differences in weight and length by ethnicity arise largely through differences at birth and growth in the early months of life. Further work will investigate relationships between exposures during pregnancy and differences in early life growth trajectories

\section{P1-286 ARE DIFFERENCES IN SELF-REPORTED HEALTH BEHAVIOURS IN EARLY PREGNANCY ASSOCIATED WITH ETHNICITY? PRELIMINARY RESULTS FROM THE BORN IN BRADFORD BIRTH COHORT STUDY}

doi:10.1136/jech.2011.142976e.78

\begin{abstract}
${ }^{1,2}$ E Petherick, ${ }^{*}$ L Fairley, ${ }^{2} \mathrm{R}$ Parslow, ${ }^{1} \mathrm{P}$ Raynor, ${ }^{3} \mathrm{D}$ Leon, ${ }^{4} \mathrm{D}$ Lawlor, ${ }^{1} \mathrm{~J}$ Wright. ${ }^{1}$ Bradford Institute for Health Research, Bradford, UK; ${ }^{2}$ Paediatric Epidemiology Group, University of Leeds, Leeds, UK; ${ }^{3}$ Department of Non-communicable disease epidemiology, London School of Hygeine and Tropical Medicine, London, UK; ${ }^{4}$ MRC Centre for Causal Analyses in Translational Epidemiology, University of Bristol, Bristol, UK
\end{abstract}

Introduction Pregnancy is a time of high motivation to initiate positive changes in health behaviours which have the potential to 